\title{
Open access colonoscopy for suspected colonic neoplasia
}

\author{
J J T TATE AND G T ROYLE \\ From the University Surgical Unit, Royal South Hampshire Hospital, Southampton
}

SUMmary An open access endoscopy service for direct referral of patients suspected to have colonic neoplasia has been analysed. In the first year of the service 137 patients were referred by 52 general practitioners. The most common reason for referral was rectal bleeding (58\%). Colonoscopy was done without outpatient consultation or barium enema examination in 130 patients: there were no complications. The diagnostic yield was $57 \%$ : 34 patients $(25 \%)$ had neoplasia (cancer 14, adenoma 20), which was higher than the yield of neoplasia in patients referred for open access double contrast barium enema during the same period. Only nine patients $(7 \%)$ needed further investigation because colonoscopy was incomplete and $21(16 \%)$ were treated by polypectomy at the diagnostic colonoscopy.

Colonoscopy is increasingly the first line investigation for large bowel disease, particularly for patients with colonic bleeding. ${ }^{1-3}$ This is because colonoscopy is potentially more accurate than barium enema for the diagnosis of colorectal neoplasia ${ }^{3+}$ and, in some cases, treatment - for example, polypectomy, can be undertaken during the examination. Referral for colonoscopy is usually restricted to hospital specialists. The majority of patients with colonic neoplasia, however, present initially to their general practitioner (GP). Where GPs have direct access to barium enema investigation the diagnostic yield among GP and hospital referred patients is similar, but those found to have a polyp also undergo endoscopic polypectomy. Open access fibreoptic sigmoidoscopy has been reported" but has the major limitation that a complete examination of the colon is not possible. We report initial results of a study of open access colonoscopy for patients with suspected colonic neoplasia.

\section{Methods}

PATIENTS

Introduction of the open access colonoscopy service

Address for correspondence: J J T Tate, FRCS, University Surgical Unit. F Level, Centre Block. Southampton General Hospital, Southampton, SOY 4 XY.

Received for publication 9 May 1988. was by personal letter to 152 of 230 GPs in the Southampton and South West Hampshire Health District whose practice was closest to the hospital at which the service was based. The total population of the district is approximately 443600 . It was suggested that patients with suspected neoplasia or rectal bleeding were particulary suitable for investigation by colonoscopy but no exclusion criteria were laid down.

Patients were referred by letter direct to the endoscopy department and not to a particular consultant. It was assumed that anorectal pathology had been excluded by the GP and all patients were sent an appointment for colonoscopy without hospital consultation or examination. An information booklet ${ }^{7}$ and bowel preparation was sent to the patient with their appointment. Bowel preparation consisted of Picolax $^{\text {TM }}$ (Ferring AB, Sweden), one sachet and X-prep ${ }^{\mathrm{TM}}$ (Napp Laboratories), $75 \mathrm{ml}$ taken together 24 hours before examination and Picolax, one sachet, alone on the morning of the examination. Patients 80 years or older were admitted to hospital one day before colonoscopy for bowel preparation to be carried out.

Patients were interviewed and examined by the endoscopist immediately before colonoscopy to ensure there were no contraindications to the procedure. Endoscopy was done, usually under sedation with diazemul $(10-20 \mathrm{mg})$ and pethidine $(50 \mathrm{mg})$ iv, 
by an experienced colonoscopist or a trainee under supervision.

After the procedure the patient was given the result and referred back to their GP for further management. A full report was sent to the GP by post, or in cases of urgency, by telephone.

In order to provide a comparison, a prospective audit was done with 100 consecutive patients referred for diagnostic colonoscopy from the surgical outpatient department, all of whom had had previous rigid sigmoidoscopy, and 100 consecutive referrals from GPs for double contrast barium enema examination (open access barium enema) in the same hospital.

\section{Results}

In one year 137 referrals were received from 52 GPs in 38 practices. Six patients did not keep their appointment for colonoscopy - one was moving out of the area, two had remission of symptoms and did not wish any investigation, and three preferred not to have endoscopy. One patient presenting to the endoscopy unit had jaundice and it was felt colonoscopy was contraindicated (subsequent gastroscopy showed oesophageal varices). The increased workload generated by the service (approximately three examinations per week) was managed within existing endoscopy sessions, mainly by increasing the number of examinations per session.

Colonoscopy was carried out on 130 patients (age range $20-83$, median 65 years). The time from referral to examination was three to 39 days (median 23 days) excluding five patients who declined their first appointment because it was inconvenient. The presenting symptoms and indications for colonoscopy are listed in the Table. Evidence of bleeding (overt or occult bleeding per rectum or iron deficiency anaemia) was present in 76 patients $(58 \%)$. Abdominal pain was the second most

Table Presenting symptoms in 130 patients undergoing open access colonoscopy and their predictive value for cancer

\begin{tabular}{lccc}
\hline $\begin{array}{l}\text { Symptom (alone or as one } \\
\text { of several symptoms) }\end{array}$ & $n$ & $(\%)$ & $\begin{array}{l}\text { +ve predictive } \\
\text { value for cancer }\end{array}$ \\
\hline Bleeding per rectum & 49 & $(38)$ & $18 \%$ \\
Abdominal pain & 46 & $(35)$ & $7 \%$ \\
Change of bowel habit & 34 & $(26)$ & $26 \%$ \\
Diarrhoea & 27 & $(21)$ & $7 \%$ \\
Constipation & 16 & $(12)$ & 0 \\
+ve faecal occult blood test* & 16 & $(12)$ & $37 \%$ \\
Anaemia (iron deficient) & 11 & $(8)$ & $9 \%$ \\
Other & 19 & $(15)$ & - \\
\end{tabular}

*All patients were symptomatic - that is, stool test was not part of a screening programme.

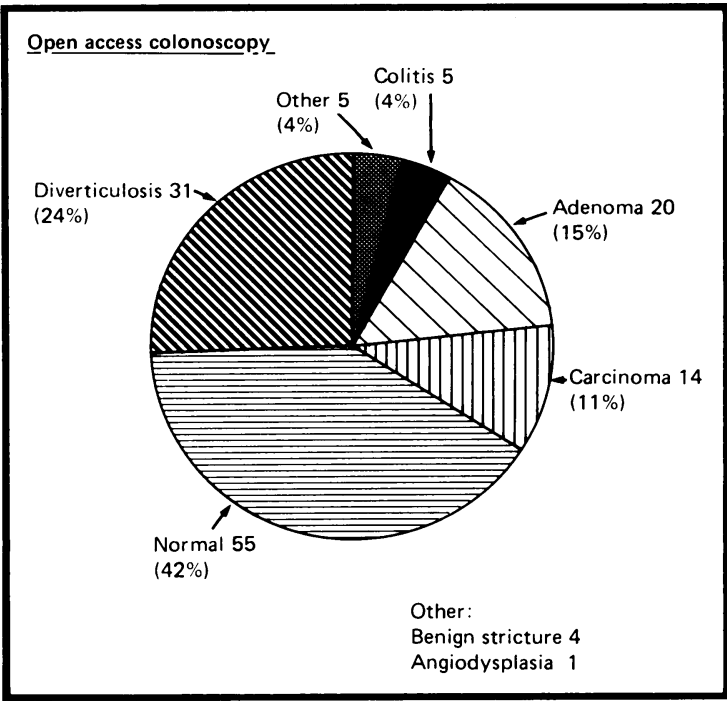

Fig. 1 Diagnosis at colonoscopy in 130 patients referred by $G P$.

common complaint (46 patients $(35 \%)$ ) and in half of these was the sole symptom.

The colonoscope was passed to the caecum in 105 patients $(81 \%)$. In a further 16 patients a diagnosis was established although the whole colon was not examined (cancer 11, non-malignant stricture four, irritable bowel syndrome one). Thus no definite result was obtained in nine patients $(7 \%)$, including two in whom colonoscopy was prevented by unsatisfactory bowel preparation, and these required further investigation. No complications occurred during colonoscopy.

Colonoscopy in all 130 patients gave a total diagnostic yield of $57 \%$ (Fig. 1). Neoplastic disease was found in $33(25 \%)$; cancer in 14 (five Duke's stage $\mathrm{A}$; three stage $\mathrm{B}$; six stage $\mathrm{C}$ ) and adenomatous polyps in 20 . In two cases of cancer the lesion, although invasive, was contained within an adenomatous polyp and after a careful review of the histology both were found to fulfil the criteria for endoscopic management. ${ }^{*}$ These tumours were assumed to be Duke's stage A. A total of 33 adenomatous polyps were removed from 19 patients, seven patients had multiple polyps, and one patient with a large villous adenoma of the rectum was referred for surgery. Two cancers and six polyps were proximal to the splenic flexure.

The diagnostic yield in hospital referred colonoscopy patients (Fig. 2b) was similar to that for the open access colonoscopy patients whereas the yield from GP referred open access barium enemas (Fig. 2a) was lower and the proportion of cases of neoplasia was less than for open access colonoscopy. 




Fig. 2 Diagnosis in 100 consecutive patients referred for: (a) barium enema (GP referrals); (b) colonoscopy (surgical outpatient referrals).

\section{Discussion}

Direct referral for colonoscopy should offer increased diagnostic accuracy for mucosal disease and, by combining polypectomy with the diagnostic investigation, reduce the number of patients requiring multiple procedures. The diagnostic yield in patients referred by their GP for open access colonoscopy (OAC) was greater than in those patients referred for barium enema and similar to that of hospital referred patients. This applies not only to the diagnosis of neoplastic lesions but also for other mucosal diseases such as colitis. In addition, 21 patients $(16 \%)$ had definitive treatment (polypectomy) during their diagnostic examination saving these patients a second procedure. A negative or normal examination is also of importance, "however, not least because the patient can be reassured that their symptoms are innocent. Colonoscopy appears to be more specific for the exclusion of mucosal disease than barium enema'11" and therefore a negative result may be of greater value.

Colonoscopy does carry a greater risk of complications than barium enema. This small risk must be weighed against the increased accuracy and therapeutic opportunity. The number of patients in this study is relatively small but we did not encounter any complications, endoscopic or medical, among patients referred for open access colonoscopy despite $14 \%$ being 80 years or over and approximately $30 \%$ having coexisting diseases such as ischaemic heart disease, diabetes mellitus or chronic respiratory disease. Thus, we have encountered no problems because patients had not had a prior consultation and examination at the hospital.

Many hospitals allow GPs to refer patients for radiological investigation of the gastrointestinal tract but not for endoscopy. Selection of patients by general practitioners for open access upper gastrointestinal investigation is usually as good as that of their hospital colleagues " and sometimes better."

We have shown a similar result for large bowel investigation. We would not suggest, however, that endoscopy is the method of choice in every case. The selection of patients likely to have mucosal abnormality is important otherwise the service will be unable to meet demand and potential cost benefit will be lost." Some of the patients referred during this study might have been considered unsuitable for primary colonoscopy, for example, the 23 patients with abdominal pain without associated rectal bleeding or two patients who had palpable rectal tumours (one malignant, one benign). No detailed advice was given to GPs, however, on which patients to refer and the comparison colonoscopy group suggests that there is similar scope for improved patient selection among hospital practitioners. More efficient use of existing endoscopy lists, as suggested by a Working Party of the British Socicty of Gastroenterology, ${ }^{13}$ could provide the additional facilities to offer open access colonoscopy.

Symptoms alone are not always reliable for the selection of patients with mucosal disease. Rectal bleeding is one that may be particularly appropriate but non-bleeding patients should not be excluded from open access colonoscopy. The single most accurate predictor of neoplasia in this study was a positive Haemoccult faccal occult blood test ( ${ }^{\mathrm{TM}}$ Smith Kline Instruments Inc) which has been suggested previously as being of value in the identification of patients likely to have neoplasia. ${ }^{14}$

An alternative investigation is fibreoptic sigmoidoscopy which, like barium enema, requires no sedation. Worthwhile results have been reported 
with an open access service ${ }^{6}$ but, unlike barium enema and colonoscopy, complete examination of the colon cannot be achieved. Approximately 15$40 \%$ of patients with neoplasia have disease proximal to the splenic flexure ${ }^{1510}$ and if a lesion is present in the distal colon a proximal synchronous lesion will not be excluded. Furthermore adenomatous polyps that are found should not be removed unless full bowel preparation has been given. Thus flexible sigmoidoscopy must be regarded as preparatory to the main investigation (whether barium enema or colonoscopy) in the large majority of patients. When colonoscopy is incomplete, however, it may provide no more information than could be obtained by flexible sigmoidoscopy. The reported rate of complete examination at colonoscopy varies but for an open access diagnostic service to be of value complete colonoscopy must be avhieved in a high proportion of cases. This requires an experienced endoscopist to be present at every examination.

In summary we have found open access colonoscopy to be well utilised by GPs with a high yield of colonic neoplasia $(25 \%)$, with a higher than expected proportion of early cancers (Duke's A), and nonneoplastic mucosal lesions (8\%). As well as having a high sensitivity for mucosal abnormalities colonoscopy is also specific which is important for any diagnostic service. The opportunity to treat some patients during their diagnostic examination is an advantage of open access colonoscopy over open access upper gastrointestinal endoscopy which is already well established in many centres. ${ }^{13}$ The aim of this study was to investigate whether open access colonoscopy is a practical and advantageous diagnostic method. We suggest that our results have shown this to be so and conclude that all medical practitioners should be able to refer patients for primary colonoscopy when mucosal abnormalities are suspected.

We thank the Wessex Medical School Trust, Television South, Key Med, ICL and Norwich Eaton who have supported this project. We thank also Professor I Taylor for his advice, the Department of Radiodiagnosis for permission to report results, and the staff of the Endoscopy Unit, Royal South Hampshire Hospital.
References

1 Lindsay DC, Freeman JG, Cobden I, Record CO. Should colonoscopy be the first choice investigation for colonic disease? Br Med J 1988; 296: 167-9.

2 Guillem JG, Forde KA, Treat MR, Neugut AI, Bodian CA. The impact of colonoscopy on the early detection of colonic neoplasms in patients with rectal bleeding. Ann Surg 1987; 206: 606-11.

3 Aldridge MC, Sim AJW. Colonoscopy findings in symptomatic patients without $\mathrm{X}$-ray evidence of colonic neoplasms. Lancet 1986; i: 833-4.

4 Swarbrick ET, Fevre DI, Hunt RH, Thomas BM, Williams CB. Colonoscopy for unexplained rectal bleeding. Br Med J 1978; ii: 1685-7.

5 Vellacott KD, Virjee J. Audit on the use of barium enema. Gut 1987; 27: 182-5.

6 Vellacott KD, Roe AM, Mortensen NJM. An evaluation of a direct access flexible fibreoptic sigmoidoscopy service. Ann R Coll Surg Engl 1987; 69: 149-52.

7 Hadley A. Having a colonoscopy: a guide to the test. Southend-on-Sea: Key Med, 1986.

8 Morson BC, Whiteway JE, Jones EA, Macrae FA, Williams CB. Histopathology and prognosis of malignant colorectal polyps treated by endoscopic polypectomy. Gut 1984; 24: 437-44.

9 Jones R. Open access endoscopy. Br Med J 1985; 291: 424-6.

10 Durdey P, Weston PMT, Williams NS. Colonoscopy or barium enema as initial investigation of colonic disease. Lancet 1987; ii: 549-51.

11 Holdstock G, Wiseman M, Loehry CA. Open access endoscopy service for General Practitioners. Br Med J 1979; i: 457-9.

12 Conry BG, McLean AM, Farthing MJG. Open access endoscopy or barium meal? Br Med J 1985; 291: 900-1.

13 Axon ATR, Bottrill PM, Campbell D. Results of a questionaire concerning the staffing and administration of endoscopy in England and Wales. Gut 1987; 28: 152730.

14 Farrands PA, O'Reagan D, Taylor I. An assessment of occult blood testing to determine which patients with large bowel symptoms require urgent investigation. $\mathrm{Br} J$ Surg 1985; 72: 835-7.

15 Shinya H, Wolff WI. Morphology, anatomic distribution and cancer potential of colonic polyps. Ann Surg 1979; 190: 679-83.

16 Matek W, Hermanek P, Demling L. Is the adenomacarcinoma sequence contradicted by the differing location of colorectal adenomas and carcinomas? Endoscopy 1986; 18: 17-9. 